\title{
WRITING FOR THE WIDER PUBLIC - READABILITY OF PUBLICLY AVAILABLE BOARD REPORTS
}

\author{
Benedict Okonjo 1,2, Parul Kaithwas 1,3, Jing Miao', Mark Mackayl, Vanessa North 1 \\ 1. UniSA Clinical \& Health Sciences, University of South Australia, Adelaide, South Australia, Australia \\ 2. AOA National Joint Replacement Registry, SAHMRI North Terrace, Adelaide, South Australia, Australia. \\ 3. Evanston Park Surgery, 18-20 Alexander Avenue, Evanston Park SA 5116 , Australia.
}

Correspondence: okoby001@mymail.unisa.edu.au

\section{ABSTRACT}

\section{OBJECTIVE}

This work aims to evaluate the readability of publicly available board reports from the Local Health Networks (LHNs) in South Australia and the National Health Service (NHS) Trusts in England.

\section{METHOD}

Publicly available board reports from the LHNs in South Australia and NHS Trusts in England were identified, screened, and evaluated from January 2020 to August 2020.

\section{RESULTS}

The average Flesch Reading Ease score for all LHNs reviewed ranged from $34 \pm 10.2$ to $57 \pm 0.0$ (Difficult to Fairly Difficult). In comparison, the average Flesch Reading Ease score for all the NHS Foundation Trusts ranged from $46 \pm 1.7$ to $60 \pm 3.0$ (Difficult to Standard). The average Reading Ease score for metropolitan and non-metropolitan LHNs was $43 \pm 8.1$ and 41 \pm 6.0 (Difficult to read). In contrast, the average Reading Ease score for metropolitan and non-metropolitan NHS Trust was Fairly Difficult with $53 \pm 4.2$ and $50 \pm 3.5$ respectively.

\section{CONCLUSION}

The evaluation results suggest that there is scope for improving the quality of publicly available board reports from the boards reviewed in terms of their readability by the public.

\section{KEYWORDS}

Public Reporting, Governance Board, Health Service Management, Readability, Public Engagement, Accountability, Transparency 


\section{BACKGROUD}

Recently, healthcare organisations have increasingly been placed under the control and direction of healthcare governing boards. [1-3] In 2019, the South Australian Government introduced governing board oversight for all the Local Health Networks (LHNs) as a strategic reform of $\dagger$ he healthcare system. [4] In establishing the boards, a charter was also created. The charter details the roles and responsibilities of the Boards. [5] This included the timely publication of the agenda and minutes of meetings as a mechanism to ensure transparency and accountability, and as a means to gain public engagement.

The English National Health Service (NHS) has a more extended history of striving to achieve good board governance. Other countries, including Australia, have compared their health systems to the NHS. Both nation's healthcare governance boards are primarily responsible for providing strategic oversight and guidance to health facilities and systems within their jurisdictions as required mainly through law. $[5,6]$

Public reporting is a critical mechanism for stakeholder engagement and ensuring accountability and transparency of governing boards. [7-10] Accountability "encompasses the procedures and processes by which one party justifies and takes responsibility for its activities such as for achieving various organisational goals. [7]" Board reports often contain valuable information relating to resource allocation and future plans for healthcare delivery. $[9,11]$ It is crucial that the public, who are primary stakeholders of the boards, understand the reasons, context, and environment for governance boards' plans and decisions. [1,12] Primary stakeholders are individuals that directly benefit or are impacted by decisions or actions caused by others. [13] Existing research suggests that more desirable health outcomes are achieved when the public or consumers are appropriately engaged and participate in decision-making. [14,15] The NHS Trusts and LHNs boards are required by legislation to engage their communities in decision-making processes by publishing their board meeting reports on accessible websites free of charge. [5,6] Indeed, the charter of the LHNs in South Australia require Boards to engage with the community and therefore reports should be accessible. [5]
The notion of readability matters when considering reports published for the general public. Readability can be defined as how easy a text is to understand due to the style of writing. [16] The use of readability formulae have been the most common and quickest way to measure text readability. [16] Developed in the early 20th century, most readability formulae are simple algorithms that aid in the objective evaluation of the readability of a text.

Much of the current literature examining governing board public reports have so far focused on issues such as the clinical focus and content of board meetings reports. $[1,3,17]$; the engagement of health service boards with quality-of-care issues [2,18]; public reporting of health outcomes, quality and costs [19-21]; and the ease of obtaining information from boards. [22] There has been little research focusing on the quality of these board reports in terms of readability by the general public. [20]. Therefore, this work aims to examine the readability of publicly available board reports from the Local Health Networks in South Australia and the NHS Trusts in England.

\section{RESEARCH METHOD}

\section{Data Sample Collection and Screening}

Publicly available board reports were collected from the web pages of all ten Local Health Networks (LHNs) in South Australia (SA) from January 2020 to August 2020.

For NHS Trusts in England, a total of 493 NHS Trusts were initially identified through a comprehensive web search. The identified NHS Trusts were then screened using the following criteria or steps.

First, all abolished NHS Trusts were removed from the sample. Second, NHS Foundation Trusts were selected because they are the newest type of NHS Trusts. Third, NHS Foundation Trusts with a hospital component, similar to the LHNs in SA, were selected.[23] Fourth, NHS Foundation Trusts that were rated "outstanding" in the Care Quality Commission (CQC)'s "well-led" and "overall" rating scales for 2020 were selected.[24,25] ) Finally, duplicate NHS Foundation Trusts were removed, bringing the final sample number to 9. The published board reports from the 9 NHS Foundation Trusts were then collected from January 2020 to August 2020. The flowchart in Figure 1 below illustrates the selection, as mentioned above, for the NHS Trusts. 


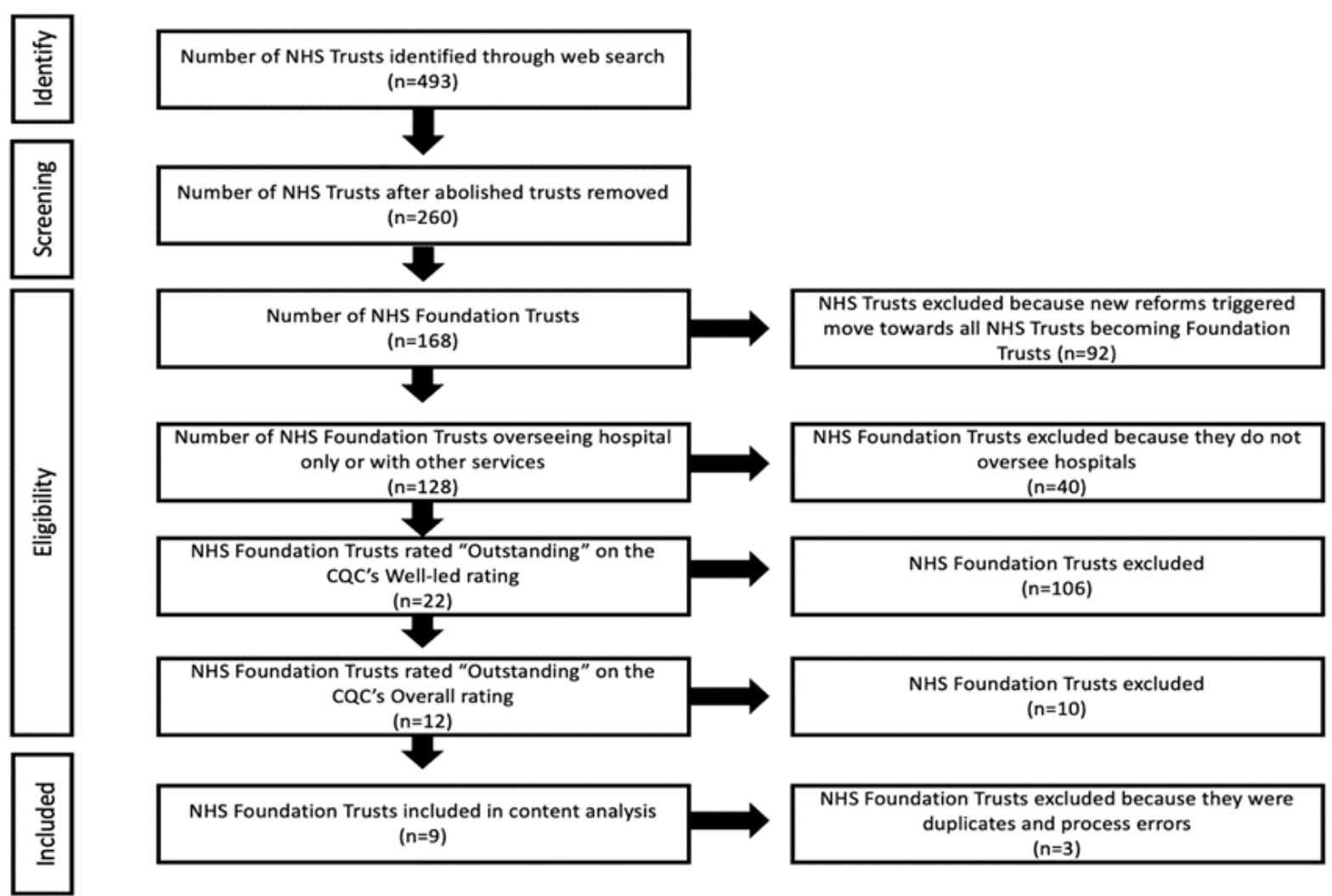

\section{Data Analysis}

We used the Flesch Reading Ease Score to evaluate the readability of publicly available board reports from the Local Health Networks in South Australia and the NHS Trusts in England. The Flesch Reading Ease Score is a readability test developed by Rudolph Flesch in 1948. [26] The Flesch Reading Ease Score is a well-established instrument often freely available in word-processing software such as Microsoft ${ }^{\circledR}$ Word. It often proxies as a gold-standard comprehension test and has a correlation coefficient of $>0.9$ with other comprehension tests. [27]

The test calculates the level of education a person needs to easily read a piece of text by assessing the average sentence length and syllables per word.[27] A web-based application called "Readable", which uses the Flesch mathematical formula to measure the readability of each board report collected, was applied: [16,28,29]

$$
\begin{aligned}
206.835-1.015 & \left(\frac{\text { total words }}{\text { total sentences }}\right) \\
& -84.6\left(\frac{\text { total syllables }}{\text { total words }}\right)
\end{aligned}
$$

The Flesch Reading Ease formula scores texts between 0 to 100. A higher score means a text is more readable, and a lower score means the text is less readable.

\section{Grade Scale}

We used the reading grade scale corresponding to the United States (US) grade level of education, as this is the most utilised grade scale in publications. [16] (16). As shown in Table 1, the US school grade levels are equivalent to the Australian education framework, and one year ahead of the United Kingdom (UK) schooling system. [30] 
TABLE 1: US AND AUSTRALIAN SCHOOL GRADE LEVELS

\begin{tabular}{|l|l|l|}
\hline Flesch Reading Ease Score & US \& Australian education level & Readability Rating \\
\hline $0-29$ & College graduate & Very difficult \\
\hline $30-49$ & High school or 1-2 years of college & Difficult \\
\hline $50-59$ & 10th-12th Grade & Fairly difficult \\
\hline $60-69$ & 8th-9th Grade & Standard \\
\hline $70-79$ & 7th Grade & Fairly easy \\
\hline $80-89$ & 6th Grade & Easy \\
\hline $90-100$ & 5th Grade & Very Easy \\
\hline
\end{tabular}

TABLE 2: SHOWS THE TOTAL NUMBER OF BOARDS REPORTS REVIEWED FROM JANUARY 2020 TO AUGUST 2020

\begin{tabular}{|c|c|c|}
\hline Regions & Name of Health Service & $\begin{array}{c}\text { Board Reports Reviewed } \\
\text { (Jan 2020 - Aug 2020) }\end{array}$ \\
\hline \multirow{10}{*}{ 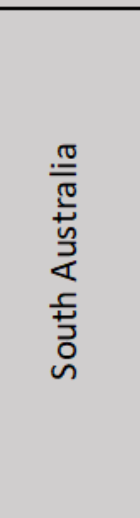 } & Barossa Hills Fleurieu Local Health Network & 7 \\
\hline & Central Adelaide Local Health Network & 3 \\
\hline & Eyre and Far North Local Health Network & 6 \\
\hline & Flinders and Upper North Local Health Network & 7 \\
\hline & Limestone Coast Local Health Network & 7 \\
\hline & Northern Adelaide Local Health Network & 7 \\
\hline & Riverland Mallee Coorong Local Health Network & 8 \\
\hline & Southern Adelaide Local Health Network & 7 \\
\hline & Women's and Children's Health Network & 5 \\
\hline & Yorke and Northern Local Health Network & 6 \\
\hline \multirow{9}{*}{ 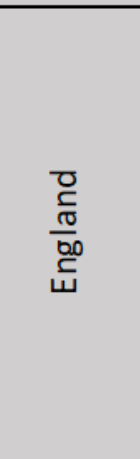 } & Kingston Hospital NHS Foundation Trust & 3 \\
\hline & Royal Papworth Hospital NHS Foundation Trust & 6 \\
\hline & Salford Royal NHS Foundation Trust & 5 \\
\hline & South Warwickshire NHS Foundation Trust & 6 \\
\hline & The Christie NHS Foundation Trust & 1 \\
\hline & The Newcastle Upon Tyne Hospitals NHS Foundation Trust & 5 \\
\hline & The Royal Marsden NHS Foundation Trust & 2 \\
\hline & University Hospitals Bristol and Weston NHS Foundation Trust & 2 \\
\hline & Western Sussex Hospitals NHS Foundation Trust & 3 \\
\hline & Total Board Reports Reviewed & 96 \\
\hline & Average Board Reports Reviewed & 5 \\
\hline \multicolumn{2}{|r|}{ Maximum Number of Reports Reviewed per Health Service Board } & 8 \\
\hline \multicolumn{2}{|r|}{ Minimum Number of Reports Reviewed per Health Service Board } & 1 \\
\hline
\end{tabular}

\section{RESULT}

For the LHNs in SA (Figure 2), the average ( \pm standard deviation) Flesch Reading Ease score for the metropolitan, non-metropolitan, and state-wide local health network was $43 \pm 8.1$ (Difficult: College Level), $41 \pm 6.0$ (Difficult: College Level) and $57 \pm 0.0$ (Fairly Difficult: High School Senior Level), respectively. All the metropolitan and non-metropolitan local health networks had reading ease scores less than 50
(Difficult to read). Flinders and Upper North Local Health Network, a non-metropolitan organisation, had the most difficult board reports to read with an average score of $34 \pm$ 10.2 (College Level). In contrast, the State-wide LHN had a comparably more desirable reading ease score of $57 \pm 0.0$ (Fairly Difficult). No LHN had a reading ease score of more than 60 (Standard Readability Level). The average Flesch Reading Ease score for all LHNs reviewed ranged from 34 to 57 (Difficult to Fairly Difficult). 


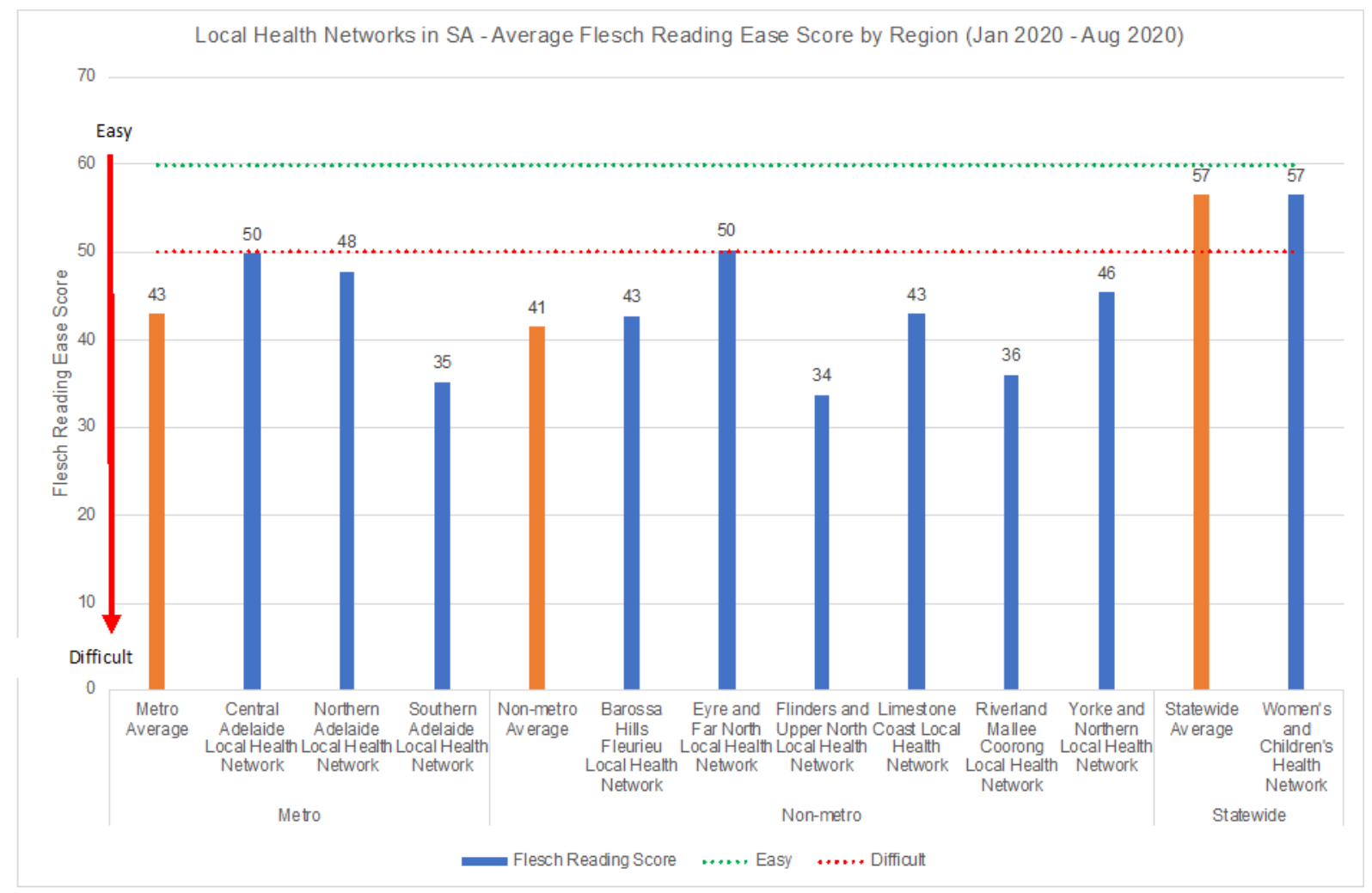

FIGURE 3: NHS FOUNDATION TRUSTS IN ENGLAND - AVERAGE FLESCH READING EASE SCORE BY REGION (JAN 2020 - AUG 2020)

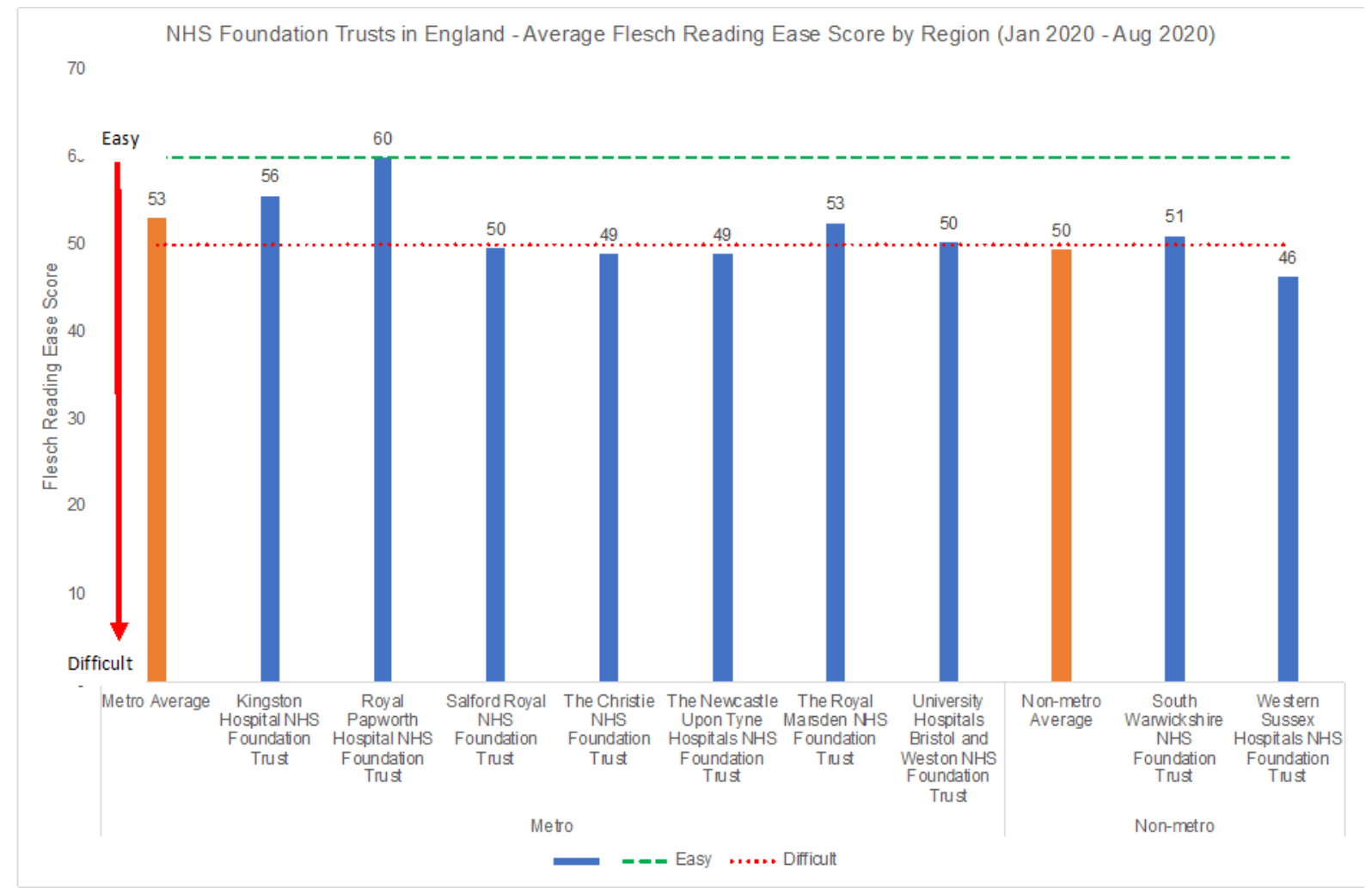


For the NHS Foundation Trusts in England (Figure 3), the average ( \pm standard deviation) Flesch Reading Ease score for the metropolitan and non-metropolitan was $56 \pm 4.2$ (Fairly Difficult: High School Senior Level) and $50 \pm 3.5$ (Difficult: College Level), respectively. 3 metropolitan NHS Foundation Trust had reading ease scores between 50 and 60 (Fairly Difficult to Standard). The NHS Foundation Trust,
Royal Papworth Hospital NHS Foundation Trust had a reading ease score of $60 \pm 3.0$ (Standard: Grade 8-9). In contrast, a non-metropolitan NHS Foundation Trust, Western Sussex Hospitals NHS Foundation Trust, had the most difficult to read score of $48 \pm 1.7$. The average Flesch Reading Ease score ranged from 46 to 60 (Difficult to Standard).

TABLE 3: DISPLAYS THE MEAN, STANDARD DEVIATION, MAXIMUM AND MINIMUM FLESCH READING EASE SCORES FOR NHS TRUSTS AND LHNS.

\begin{tabular}{|c|c|c|c|c|c|}
\hline Regions & Name of Health Service & $\begin{array}{l}\text { Mean Flesch } \\
\text { Reading Ease } \\
\text { Score }\end{array}$ & $\begin{array}{c}\text { StdDev. Flesch } \\
\text { Reading Ease Score }\end{array}$ & $\begin{array}{l}\text { Max. Flesch Reading } \\
\text { Ease Score }\end{array}$ & $\begin{array}{l}\text { Min. Flesch Reading } \\
\text { Ease Score }\end{array}$ \\
\hline \multirow{13}{*}{ 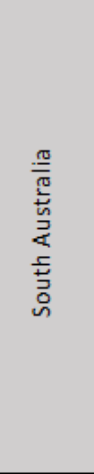 } & Barossa Hills Fleurieu Local Health Network & 43 & 2.4 & 46 & 38 \\
\hline & Central Adelaide Local Health Network & 50 & 2.3 & 53 & 48 \\
\hline & Eyre and Far North Local Health Network & 50 & 1.7 & 52 & 47 \\
\hline & Flinders and Upper North Local Health Network & 34 & 10.2 & 50 & 22 \\
\hline & Limestone Coast Local Health Network & 43 & 1.5 & 45 & 41 \\
\hline & Northern Adelaide Local Health Network & 48 & 6.8 & 54 & 34 \\
\hline & Riverland Mallee Coorong Local Health Network & 36 & 1.8 & 38 & 33 \\
\hline & Southern Adelaide Local Health Network & 35 & 18.5 & 44 & -7 \\
\hline & Women's and Children's Health Network & 57 & 3.3 & 60 & 52 \\
\hline & Yorke and Northern Local Health Network & 46 & 4.3 & 52 & 41 \\
\hline & Metropolitan LHNs & 44 & 8.1 & 50 & 25 \\
\hline & Non-metropolitan LHNs & 42 & 6.0 & 47 & 37 \\
\hline & State-wide LHN & 57 & 0.0 & 60 & 52 \\
\hline \multirow{11}{*}{ 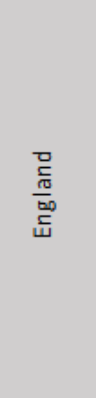 } & Kingston Hospital NHS Foundation Trust & 56 & 0.8 & 56 & 55 \\
\hline & Royal Papworth Hospital NHS Foundation Trust & 60 & 3.0 & 64 & 57 \\
\hline & Salford Royal NHS Foundation Trust & 50 & 5.0 & 55 & 42 \\
\hline & South Warwickshire NHS Foundation Trust & 51 & 3.4 & 56 & 47 \\
\hline & The Christie NHS Foundation Trust & 49 & 0.0 & 49 & 49 \\
\hline & The Newcastle U pon Tyne Hospitals NHS Foundation Trust & 49 & 3.0 & 52 & 46 \\
\hline & The Royal Marsden NHS Foundation Trust & 53 & 1.5 & 54 & 52 \\
\hline & University Hospitals Bristol and Weston NHS Foundation Trust & 50 & 0.7 & 51 & 50 \\
\hline & Western Sussex Hospitals NHS Foundation Trust & 46 & 1.7 & 48 & 45 \\
\hline & Metropolitan NHS Trusts & 52 & 4.2 & 54 & 50 \\
\hline & Non-metropolitan NHS Trusts & 49 & 3.5 & 52 & 46 \\
\hline
\end{tabular}

\section{DISCUSSION}

The public health sector represents a significant investment of resources. For instance, the total spending on health in 2019-20 is estimated to be $\$ 81.8$ billion, $16.3 \%$ of the Australian Government's total expenditure.[31] Therefore, it is imperative that there is transparency and accountability by those charged with running public health care organisations and that the wider public can engage with public records. This work set out to assess the readability of publicly available board reports from the Local Health Networks in South Australia and the NHS Trusts in England. The result suggests there is scope for improving the quality of publicly available board reports in terms of their readability by the general public.
Perhaps the most striking finding is that only one governing board, the Royal Papworth Hospital NHS Foundation Trust, had board reports with an average Flesh Reading Ease score of $60 \pm 3.0$ (Standard: Grade 8-9). A text with a score of 60 or more is considered accessible to the general public.[30] Other governing boards had reports ranging from Difficult [34] to Fairly Difficult. [59] This means that only members of the public with College or High School Senior Educational Levels can easily understand the contents of the publicly available reports. According to the Australian Charter of Healthcare Rights, the general public, without exemption, have the right to be informed and participate in health service planning and decision making in a clear and open way (32). In order to achieve meaningful public engagement, transparency and accountability, board 
reports should be created with the aim of informing the least educated or literate members of the public. Although the solution could simply mean publishing report versions specifically prepared to cater to those with a lower literacy level, it has been suggested that such reports could lead to disengagement. [33,34] This may be so for subject matter experts but not necessarily the general public, who often are individuals with low literacy levels. [30,35]

Another important finding was that the most difficult board report to read belonged to a non-metropolitan organisation, Flinders and Upper North Local Health Network, with a Reading Ease Score of $34 \pm$ 10.2. Generally, members of the public living in non-metropolitan areas tend to have only high school educational level.[36] On average, according to the Australian Institute of Health and Welfare, Australians living in rural and remote areas have poorer health outcomes partly due to a level of disadvantage related to education. [37] Furthermore, the other metropolitan and non-metropolitan LHNs had scores less than 50 (Difficult to read). In contrast, the average Reading Ease score for metropolitan and non-metropolitan NHS Trust was rated Fairly Difficult with $53 \pm 4.2$ and $50 \pm 3.5$, respectively. The difficult reading levels suggest that even if the public is interested in the publicly available reports, it is likely that there would be low levels of public engagement with the reports as a consequence of how the material is written

Readability formulae have been subject to criticism as being too simplistic. For example, the formulae do not consider the readers' comprehension and detect the use of concise but technical words.[33,34,38] However, even critics contend that results derived from readability formulae could serve as a foundation for further analysis on other aspects of readability, such as the readers understanding of the context.[30,34,39] There are calls for developing more complex instruments that objectively examine visual or infographics used by international organisations such as the World Health Organisation to communicate complex information to the general public.[30] The analysis of video communications used by Governance Boards in England NHS was outside the scope of this research but could serve as an additional means of public reporting and engagement by LHNs in South Australia.

The result above reflects the need to review the relevant laws on public reporting to include a focus on the quality of published reports in terms of readability. This will ensure improved public engagement and not merely compliance to publish reports.

Our findings in this evaluation open the door to future research to review the readability of publicly available reports from other governing boards in Australia and England as a proxy to accessing the degree of genuine public engagement by governing boards.

\section{ETHICS APPROVAL}

Not applicable.

\section{COMPETING INTERESTS}

The authors declare no competing interests.

\section{ACKNOWLEDGEMENTS}

This article stemmed from a capstone project undertaken for a Master of Health Services Management degree. The authors wish to acknowledge the contribution made to the original project by Ma Alexandra Celine Bartolome and Kinjal Atik Kumar Shah. This research did not receive any specific funding.

\section{Reference}

1. Endacott R, Sheaff R, Jones R, Woodward V. Clinical focus and public accountability in English NHS Trust Board meetings. Journal of Health Servies Research \& Policy. 2013;18(1):13-20.

2. McDonagh KJ, Umbdenstock RJ. Hospital Governing Boards: A Study of Their Effectiveness in Relation to Organizational Performance. Journal of Healthcare Management. 2006;51(6):377.

3. Bismark MM, Walter SJ, Studdert DM. The role of boards in clinical goverance: activities and attitudes among members of public health service boards in Victoria. Australian Health Review. 2013; 37:682-7.

4. Hlipala L. Governing Board Members sought for South Australia's public health system Local Health Networks: HardyGroup; 2020 [Available from:

https://hardygroupintl.com/blog/governing-boardmembers-sought-for-south-australias-public-healthsystem-local-health-networks/.

5. Health Care (Governance) Amendment Act (SA) (2018).

6. Health and Social Care Act, (UK)(2012). 
7. O'Hagan J, Persaud D. Creating a culture of accountability in health care. Health Care Manag (Frederick). 2009;28(2):124-33.

8. Mitton C, Smith N, Peacock S, Evoy B, Abelson J. Public participation in health care priority setting: A scoping review. Health Policy. 2009;91 (3):219-28.

9. Wheeler S, Mackay J, Moody L, D'Souza J, Gilbert J. Engaging Patient and Family Advisors in Health-Care System Planning: Experiences and Recommendations. Journal of patient experience.

2019;7(3):237437351984034-337.

10. ACSQHC. Public reporting of safety and quality in public and private hospitals. Australia; 2019.

11. Mandzila EEW, Zéghal D. Content Analysis Of Board Reports On Corporate Goverance, Internal Controls And Risk Management Evidence From France. The Journal of Applied Business Research. 2016;32(3):1-13.

12. Department of Health. Open access meetings. Australian Department of Health. n.d:1-2.

13. Amanda L. Webster. What Is a Primary Stakeholder? : bizfluent; 2019 [Available from:

https://bizfluent.com/about-6455864-definitionprimary-stakeholders.html.

14. Sharma AE, Knox M, Mleczko VL, Olayiwola JN. The impact of patient advisors on healthcare outcomes: a systematic review. BMC Health Serv Res. 2017;17(1):693-.

15. Sharma AE, Willard-Grace R, Willis A, Zieve O, Dubé K, Parker C, et al. "How Can We Talk about Patientcentered Care without Patients at the Table?" Lessons Learned from Patient Advisory Councils. J Am Board Fam Med. 2016;29(6):775-84.

16. Flinton D, Singh MK, Haria K. Readability of internetbased patient information for radiotherapy patients. Journal of Radiotherapy in Practice. 2018;17(2):142-50.

17. Watkins $M$, Jones $R$, Lindsey $L$, Sheaff R. The clinical content of NHS trust board meetings: an inital exploration. Journal of Nursing Management 2008; 16:707-15.

18. Bismark MM, Studdert DM. Governance of quality of care: a qualitative study of health service boards in Victoria, Australia. BMJ Quality and Safety. 2014;23:474-82.

19. Wadhera RK. Taking the "Public" Out of Public Reporting of Percutaneous Coronary Intervention. Journal of American Medical Association. 2017;318(15):1439-40.
20. James J. Public Reporting on Quality and Costs. Health Policy Brief. 2012:1-5.

21. Heenan M, Wood B, Taylor W. Real numbers tell real stories in health services management. Healthcare Management Forum. 2010;23:119-22.

22. Valerie W, Ruth E, Rod S, Ray J. Obtaining corporate information from NHS foundation trusts. Nursing Standard. 2009;23(42):1-3.

23. Department of Health. A Short Guide to NHS Foundation Trusts. National Health Services (NHS) 2005:1-16.

24. Care Quality Commission. The five key questions we ask: Care Quality Commission; 2018 [Available from: https://www.cac.org.uk/what-we-do/how-we-do-ourjob/five-key-questions-we-ask.

25. Care Quality Commission. Key lines of enquiry, prompts and ratings characteristics for healthcare services 2018 [1-55]. Available from:

https://www.cac.org.uk/sites/default/files/20180628\%2 OHealthcare\%20services\%20KLOEs\%20prompts\%20and \%20characteristics\%20FINAL.pdf.

26. Flesch R. A New Readability Yardstick. Journal of Applied Psychology. 1948;32(3):221-33.

27. Rughani G, Hanlon P, Corcoran N, Mair FS. The readability of general practice websites: a crosssectional analysis of all general practice websites in Scotland. British Journal of General Practice. 2021;71 (706):e391-e8.

28. Readable. Readable n.d [Available from: https://readable.com/.

29. Patel AJ, Kloosterboer A, Yannuzzi NA, Venkateswaran N, Sridhar J. Evaluation of the Content, Quality, and Readability of Patient Accessible Online Resources Regarding Cataracts. Seminars in Ophthalmology. $2021 ; 36(5-6): 384-91$.

30. Ferguson C, Merga M, Winn S. Communications in the time of a pandemic: the readability of documents for public consumption. Australian and New Zealand Journal of Public Health. 2021;45(2):116-21.

31. Parliament of Australia. Health: Budget Review 2019-20 2019 [Available from:

https://www.aph.gov.au/About Parliament/Parliamen tary_Departments/Parliamentary_Library/pubs/rp/Bud getReview201920/Health.

32. Australian Commission on Quality and Safety in Health Care. Australian Charter of Healthcare Rights. ACSQHC. Sydney NSW2008. 
33. Janan $D$, Wray $D$, editors. Readability: The limitations of an approach through formulae2012.

34. Janan D, Wray D. REASSESSING THE ACCURACY AND USE OF READABILITY FORMULAE. Malaysian Journal of Learning anf Instruction. 2014; 11:127-45.

35. Rowlands G, Protheroe J, Winkley J, Richardson M, Seed PT, Rudd R. A mismatch between population health literacy and the complexity of health information: an observational study. British Journal of General Practice. 2015;65(635): e379-e86.

36. Laura Perry. Educational disadvantage is a huge problem in Australia - we can't just carry on the same: The Conversation; 2017 [Available from: https://theconversation.com/educationaldisadvantage-is-a-huge-problem-in-australia-we-cantjust-carry-on-the-same-74530.

37. Australian Institute of Health and Welfare. Rural \& remote health: Australian Government; 2019 [Available from:

https://www.aihw.gov.au/reports/rural-remoteaustralians/rural-remote-health/contents/profile-ofrural-and-remote-australians .

38. Begeny JC, Greene DJ. CAN READABILITY FORMULAS BE USED TO SUCCESSFULLY GAUGE DIFFICULTY OF READING MATERIALS? Psychology in the Schools. 2014;51 (2):198-215.

39. Wray D, Janan D. Readability revisited? The implications of text complexity. The Curriculum Journal. 2013;24(4):553-62. 